Cerebrovasc Dis 2009;27:614-615

DOI: $10.1159 / 000218072$

\section{Basilar Artery Occlusion Treated with Mechanical Thrombectomy beyond Eight Hours with Successful Recanalization and Good Functional Outcomes}

Mazen Noufal a , James W. Schmidley ${ }^{a}$, Eren Erdem ${ }^{\text {b }}$, Salah G. Keyrouz ${ }^{\text {a }}$

Departments of a Neurology and ${ }^{b}$ Radiology, University of Arkansas for Medical Sciences, Little Rock, Ark., USA

There is a growing interest in mechanical endovascular therapy for stroke patients who are ineligible for, or do not respond to, intravenous thrombolytic therapy. The effect of such interventions on functional outcome is yet to be proven. However, a narrow time window has limited wider use of these techniques, especially in the context of randomized trials. We illustrate 2 patients who underwent late but successful mechanical thrombectomy following acute basilar artery occlusion (BAO), with good functional outcomes.

\section{Patient 1}

A 67-year-old man with hypertension and hypercholesterolemia developed sudden right hemiparesis, dysarthria and lethargy. He presented to our institution $10 \mathrm{~h}$ following symptom onset. During the previous 3 weeks, he had had 2 episodes of transient leg weakness and headache. Neurological examination revealed severe lethargy, right gaze palsy, right facial weakness, deviation of the tongue to the right and right hemiparesis. The $\mathrm{Na}-$ tional Institute of Health Stroke Scale score was 15. Brain magnetic resonance imaging showed acute infarcts in the left pontine tegmentum, medial occipital and parietal lobes and cerebellum. Digital subtraction angiography, performed $17 \mathrm{~h}$ after the stroke, revealed midbasilar occlusion. Mechanical thrombectomy, using the X6 Merci retriever, followed by balloon angioplasty of a midbasilar artery stenosis was successfully performed, without procedure-related complications. Heparin was administered for $24 \mathrm{~h}$ after this procedure. Aspirin had been started upon admission.
Fig. 1. Patient 1: DWI showing restricted diffusion in the pontine tegmentum (a), angiogram, right vertebral injection showing midbasilar occlusion (b) and postthrombectomy angiogram showing recanalization of the basilar artery with atherosclerotic basilar artery stenosis (c). Patient 2: DWI showing restricted diffusion in the midbrain and cerebellum (d), angiogram, left vertebral injection showing midbasilar occlusion (e) and postthrombectomy angiogram showing recanalization of the basilar artery with no stenosis (f).
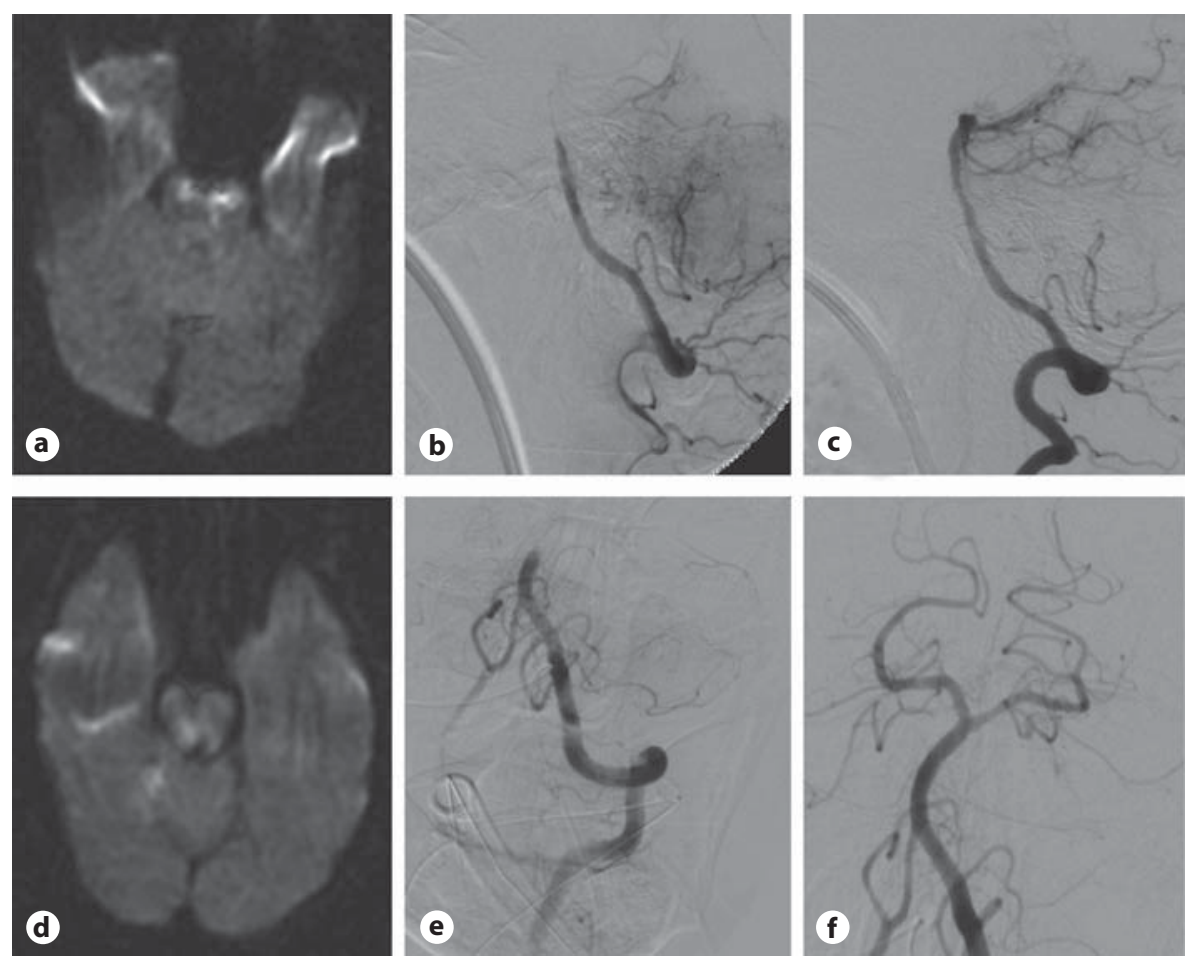
The patient's neurological exam gradually improved. He underwent inpatient rehabilitation, and 6 months after the stroke, his Modified Rankin Scale score was 0.

\section{Patient 2}

A 59-year-old man with hypertension suddenly lost consciousness. He arrived at the hospital $3 \mathrm{~h}$ later. Neurological examination revealed an intubated and mechanically ventilated, unresponsive patient with absent horizontal oculocephalic reflexes. The score on the National Institute of Health Stroke Scale was 24. Brain magnetic resonance imaging revealed acute infarcts in the dorsal midbrain, pons and right cerebellum. Digital subtraction angiography, performed $11 \mathrm{~h}$ after the stroke, revealed midbasilar artery occlusion. Mechanical thrombectomy, using the L5 Merci retriever, achieved complete vessel recanalization after 5 attempts. There were no procedure-related complications. The stroke etiology was believed to be cardioembolic. The neurological deficits gradually improved thereafter. The patient was discharged on aspirin/extended-release dipyridamole. He underwent inpatient rehabilitation, and 3 months after the stroke, his modified Rankin Scale score was 1.

\section{Discussion}

Most mechanical thrombectomy studies have excluded patients presenting beyond $8 \mathrm{~h}$ after the stroke. However, there are several reports of patients with $\mathrm{BAO}$ who had successful recanalization and good functional outcomes with thrombolysis up to $79 \mathrm{~h}$ after symptom onset [1-4], and with endovascular mechanical clot retraction up to $36 \mathrm{~h}$ after onset [5-7].

The poor prognosis in $\mathrm{BAO}$ treated with conventional therapy $[2,8,9]$, coupled with the theoretical assumption and clinical observation that the brainstem is more tolerant to longer periods of ischemia than the cerebral hemispheres [10], has led some to justify extending the window for thrombolytic and endovascular therapy in these cases.

To our knowledge, this is the first report of late mechanical thrombectomy for BAO resulting in good functional outcomes in elderly patients. Previously described patients who benefited from late mechanical thrombectomy were children or young adults, not the typical stroke population.

Both patients had decreased consciousness, gaze abnormalities and lower cranial nerve palsies, findings associated with poor clinical outcome [11]. Neither had extensive brainstem infarction on diffusion-weighted imaging (DWI), but lower sensitivity of DWI in the first $12 \mathrm{~h}$ after brainstem infarction has been reported [12]. Conversely, recent studies showed that the brainstem DWI score is an independent predictor of clinical outcome in BAO patients treated with intra-arterial thrombolysis or other means of endovascular therapy. Lower scores were associated with better functional outcomes [13, 14] (fig. 1).

Because of the expected poor prognosis based on clinical grounds, we undertook an aggressive therapeutic approach to these patients despite late presentations. The ultimate good outcome in both cases may have reflected the small size of the brainstem infarcts on pretreatment DWI. Although the results achieved may have been atypical, our aim is to underscore that late successful recanalization of BAO using mechanical thrombectomy is possible, at least in some instances. Optimal application of this technique must, of course, be guided by properly conducted clinical trials.

\section{References}

$\checkmark 1$ Cross DT 3rd, Moran CJ, Akins PT, Angtuaco EE, Diringer MN: Relationship between clot location and outcome after basilar artery thrombolysis. AJNR Am J Neuroradiol 1997;18:1221-1228.

- 2 Hacke W, Zeumer H, Ferbert A, Bruckmann H, del Zoppo GJ: Intraarterial thrombolytic therapy improves outcome in patients with acute vertebrobasilar occlusive disease. Stroke 1988;19:1216-1222.

-3 Sliwka U, Mull M, Stelzer A, Diehl R, Noth J: Long-term follow-up of patients after intra-arterial thrombolytic therapy of acute vertebrobasilar artery occlusion. Cerebrovasc Dis 2001;12:214-219.

-4 Wijdicks EF, Nichols DA, Thielen KR, Fulgham JR, Brown RD Jr, Meissner I, Meyer FB, Piepgras DG: Intra-arterial thrombolysis in acute basilar artery thromboembolism: the initial Mayo Clinic experience. Mayo Clin Proc 1997;72:1005-1013.

5 Kirton A, Wong JH, Mah J, Ross BC, Kennedy J, Bell K, Hill MD: Successful endovascular therapy for acute basilar thrombosis in an adolescent. Pediatrics 2003;112:e248-e251.

-6 Vallee JN, Crozier S, Guillevin R, Obadia M, Lo D, Barragan-Campos HM, Samson Y, Chiras J: Acute basilar artery occlusion treated by thromboaspiration in a cocaine and ecstasy abuser. Neurology 2003; 61:839-841.

7 Zaidat OO, Tolbert M, Smith TP, Alexander MJ: Primary endovascular therapy with clot retrieval and balloon angioplasty for acute basilar artery occlusion. Pediatr Neurosurg 2005;41:323-327.

8 Smith WS: Intra-arterial thrombolytic therapy for acute basilar occlusion: pro. Stroke 2007;38:701-703

-9 Voetsch B, DeWitt LD, Pessin MS, Caplan LR: Basilar artery occlusive disease in the New England Medical Center posterior circulation registry. Arch Neurol 2004;61:496-504.

10 Axer H, Grassel D, Bramer D, Fitzek S, Kaiser WA, Witte OW, Fitzek C: Time course of diffusion imaging in acute brainstem infarcts. J Magn Reson Imaging 2007;26:905-912.

11 Devuyst G, Bogousslavsky J, Meuli R, Moncayo J, de Freitas G, van Melle G: Stroke or transient ischemic attacks with basilar artery stenosis or occlusion: clinical patterns and outcome. Arch Neurol 2002;59: 567-573.

12 Kuker W, Weise J, Krapf H, Schmidt F, Friese S, Bahr M: MRI characteristics of acute and subacute brainstem and thalamic infarctions: value of $\mathrm{T}_{2}$ - and diffusion-weighted sequences. J Neurol 2002;249:33-42.

13 Cho TH, Nighoghossian N, Tahon F, Nemoz C, Hermier M, Salkine F, Derex L, Trouillas P, Froment JC, Turjman F: Brain stem diffusionweighted imaging lesion score: a potential marker of outcome in acute basilar artery occlusion. AJNR Am J Neuroradiol 2009;30:194-198.

- 14 Renard D, Landragin N, Robinson A, Brunel H, Bonafe A, Heroum C, Milhaud C: MRI-based score for acute basilar artery thrombosis. Cerebrovasc Dis 2008;25:511-516.

Mazen Noufal, MD

Departments of Neurology

University of Arkansas for Medical Sciences

4301 West Markham Street, Slot 500

Little Rock, AR 72205 (USA)

Tel. +1 501296 1165, Fax +1 501686 8689, E-Mail mnoufal@uams.edu 